Regular Article

\title{
Removal of aniline from air and water by polymers of intrinsic microporosity (PIM-1) electrospun ultrafine fibers
}

\author{
Bekir Satilmis ${ }^{\mathrm{a}, \mathrm{b}, *}$, Tamer Uyar ${ }^{\mathrm{a}, *}$ \\ a Institute of Materials Science E Nanotechnology, UNAM-National Nanotechnology Research Center, Bilkent University, Ankara 06800, Turkey \\ ${ }^{\mathrm{b}}$ Department of Chemistry, Ahi Evran University, Kirsehir 40100, Turkey
}

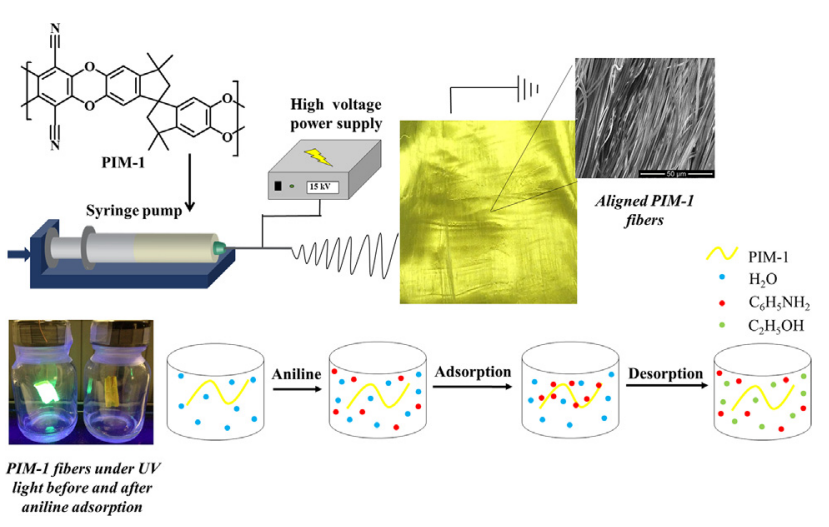

\section{A R T I C L E I N F O}

\section{Article history:}

Received 29 November 2017

Revised 12 January 2018

Accepted 19 January 2018

Available online 6 February 2018

\section{Keywords:}

Electrospinning

Polymers of intrinsic microporosity (PIM-1)

Aniline

VOC removal

Water treatment

\begin{abstract}
A B S T R A C T
This research aims to investigate the possibility of electrospun fibers from Polymers of Intrinsic Microporosity (PIM-1) as an alternative adsorbent for aniline removal from both air and aqueous solution. Adsorption properties of electrospun PIM-1 fibers were compared with powder and film form of PIM-1. While electrospun PIM-1 nanofibrous mat can adsorb $871 \mathrm{mg} \mathrm{g}^{-1}$ aniline from air, it can also adsorb $78 \pm 5.4 \mathrm{mg} \mathrm{g}^{-1}$ aniline from aqueous environment when $50 \mathrm{mg} \mathrm{L}^{-1}$ aniline solution is used. The experimental maximum adsorption capacity of electrospun PIM-1 fibers was found as $\left(q_{\mathrm{e}}\right) 138 \mathrm{mg}$ $\mathrm{g}^{-1}$. Langmuir and Freundlich isotherm models have been studied and Langmuir model found more appropriate for aniline adsorption on electrospun PIM-1 fibers. The study reveals that self-standing electrospun fibrous mat of PIM-1 has shown potential to be used as an efficient adsorbent material for the adsorption of VOCs from air and aqueous system thanks to its fast kinetic and high adsorption capacity.
\end{abstract} (c) 2018 Elsevier Inc. All rights reserved.

\footnotetext{
* Corresponding authors at: Department of Chemistry, Ahi Evran University, Kirsehir 40100, Turkey; Institute of Materials Science \& Nanotechnology, UNAMNational Nanotechnology Research Center, Bilkent University, Ankara 06800, Turkey.

E-mail addresses: bekir.satilmis1@gmail.com (B. Satilmis), uyar@unam.bilkent. edu.tr (T. Uyar).
}

\section{Introduction}

Air and water pollutions are major problems faced by today's world. The situation is further aggravated by industrialization as the pollutants released into environment without proper treatment methods [1,2]. Aniline is an important organic compound that is widely used as an intermediate in the production of pharmaceuticals, dyes and pesticides [3,4]. Aniline is a common volatile 
organic compound (VOC) that can contaminate both air and aquatic environment [5]. The presence of aniline may cause serious environmental and health problems because of its toxicity $[6,7]$. Hence, removal of aniline from air and water has attracted serious attention from researchers. A number of processes including oxidation [8], biodegradation[9], membrane separation [10], adsorption [11] and some other processes can be applied for removal of aniline [12]. From the technical and economical points of view, adsorption is regarded as one of the most promising method for aniline removal [13].

Recently, Polymers of intrinsic microporosity (PIMs), a new class of polymer, attracted significant interest due to their unusual structural feature with a backbone composed of fused rings and site of contortion [14,15]. PIMs behave as molecular sieves and show high free volume as they cannot pack space efficiently [16]. PIMs have attracted widespread attention as material for sensor $[17,18]$, catalysis $[19,20]$, membrane separation $[21,22]$, adsorbents [23] and other applications. Although a number of PIMs have been synthesized, the first member of this class, PIM-1, received the main focus as it shows great separation performance in the gas separation $[24,25]$. PIM-1, has high surface area, high thermal and chemical stability and, is soluble in common organic solvents such as tetrahydrofuran and chloroform, and can be processed in the forms of powders, membranes and fibers. PIM-1 is an organophilic polymer that is selective towards organic compounds and it shows extremely high $\mathrm{CO}_{2}$ permeability along with moderate selectivity in the membrane form. Moreover, PIM-1 membranes employed successfully in pervaporation systems to separate VOCs from aqueous system as the system has the same mass transfer mechanism with the gas separation system [26,27]. It was also studied in organic solvent nanofiltration system [28]. Recently, comparative study has been conducted by using high free volume polymer including PIM-1, poly(1- trimethylsilyl-1-propyne) (PTMSP) and poly(4-methyl-2-pentyne) (PMP). PIM-1 showed great sorption selectivity along with sorption ability for neutral dye (Solvent 35) in ethanolic solution compared to other polymer [29]. Later on, the possibility of using PIM-1 as an adsorbent and membrane material was investigated using combined process of solvent swing adsorption with solvent recovery by nanofiltration [30]. In addition to membrane form, PIM-1 has also been produced in the form of hollow fibers showing similar performances in gas separation [31,32]. The fiber form can also be produced by electrospinning method which is fairly simple and versatile way to produce three-dimensional porous adsorbents for various applications [33-39]. Electrospinning of PIM-1 is a fairly new concept that was investigated recently [40-43]. Bonso et al. [40] was first used tetrachloroethane solution to produce electrospun PIM1 fiber mat. Following this, PIM-1 mat was carbonized and used successfully as an electrode for supercapacitors. Then, the preparation of PIM/POSS fibrous membranes were developed and their oil/ water separation performances have been studied by Zhang et al. [42]. The same group also have investigated the adsorption of dyes from non-aqueous media by electrospun PIM-1 [41]. Lasseuguette et al. [43] employed different solvent system for the fabrication of electrospun PIM-1 by using tetrahydrofuran/dimethylformamide mixture.

In this study, we have prepared electrospun PIM-1 fiber and the aniline removal ability of electrospun PIM- 1 was compared with powder and film form of PIM-1 from air and water. The study revealed that all forms of PIM-1 have the ability to adsorb aniline from air within $24 \mathrm{~h}$. Moreover, PIM-1 fiber shows considerable aniline adsorption from aqueous system up to $138 \mathrm{mg} \mathrm{g}^{-1}\left(q_{\mathrm{e}}\right)$. While powder and fiber forms of PIM-1 show higher adsorption capacity than film form, fiber form of PIM-1 found more applicable in aqueous system as powder form dispersed in water and it needs additional filtration for analysis. On the other hand, fiber PIM-1 shows better stability and it maintains the fiber morphology that provides practical advantage in adsorption and reuse of adsorbent.

\section{Experimental}

\subsection{Materials}

5,5',6,6'-Tetrahydroxy-3,3,3',3'-tetramethyl-1,1'-spirobisindane (TTSBI, 98\%, Alfa Aesar) was dissolved in methanol and reprecipitated from dichloromethane before use. Tetrafluoroterephthalonitrile (TFTN, 98\%, Aldrich) was purified by sublimation; pure product collected without vacuum. Anhydrous potassium carbonate $\left(\mathrm{K}_{2} \mathrm{CO}_{3}, 99.0 \%\right.$, Fisher) was dried in an oven at $110{ }^{\circ} \mathrm{C}$ overnight before use. Dimethylacetamide (DMAc), toluene, dimethylformamide (DMF), methanol $(\mathrm{MeOH})$, chloroform $\left(\mathrm{CHCl}_{3}\right)$, tetrahydrofuran (THF), dichloromethane (DCM) and 1,1,2,2, tetrachloroethane (\% 98) were purchased from Sigma Aldrich and were used as received.

\subsection{Synthesis of PIM-1}

Synthesis of PIM-1 was performed as reported previously [44]. Yield: $62 \mathrm{~g}(90 \%)$. GPC: $M_{\mathrm{n}}=106,000, M_{\mathrm{w}}=189000, M_{\mathrm{w}} / M_{\mathrm{n}}=$ 1.78. ${ }^{1} \mathrm{H}$ NMR $\left(400 \mathrm{MHz}, \mathrm{CDCl}_{3}, \mathrm{~d}, \mathrm{ppm}\right): 6.75(2 \mathrm{H}, \mathrm{s}), 6.35(2 \mathrm{H}$ s), $2.26-2.09$ ( $4 \mathrm{H}, \mathrm{dd}), 1.40-1.10$ (broad, $12 \mathrm{H})$. ATR-IR $\left(\mathrm{cm}^{-1}\right)$ : 2995, 2864, 2239, 1605, 1446, 1264. Anal. calcd for $\mathrm{C}_{29} \mathrm{H}_{20} \mathrm{~N}_{2} \mathrm{O}_{4}$ (wt\%): C: 75.64, H: 4.37, N: 6.08 found: C: 74.6, H: 4.4, N: 5.9.

\subsection{Film preparations}

PIM-1 (0.2 g) was dissolved in $\mathrm{CHCl}_{3}(8 \mathrm{~mL})$ and stirred overnight to ensure a homogenous casting solution. The casting solution was filtered through glass wool into a glass dish. The cast solution was covered by glass funnel and left for $48 \mathrm{~h}$ to allow solvent evaporation. The freshly formed film was removed from the glass dish with the help of an ethanol/water mixture (1:1). Then it was dried in an oven at $110^{\circ} \mathrm{C}$ overnight.

\subsection{Electrospinning}

PIM-1 powder was dissolved in 1,1,2,2-tetrachloroethane at the concentration of $23 \%(\mathrm{w} / \mathrm{v})$. The PIM-1 solution was stirred at $60{ }^{\circ} \mathrm{C}$ for $1 \mathrm{~h}$ and left stirring overnight at room temperature and degassed for $15 \mathrm{~min}$ prior to use. Following that, about $2 \mathrm{~mL}$ of the PIM- 1 solution was placed in a $3 \mathrm{~mL}$ syringe, which was equipped with a blunt metal needle with an inner diameter of $0.5 \mathrm{~mm}$ and the syringe was positioned horizontally on the syringe pump ( $\mathrm{K}_{\mathrm{D}}$ Scientific, KDS 101). Metal plate collector was covered by an aluminum foil then placed across the syringe to collect microfibers. Extensive optimization studies have been performed for the electrospinning and the applied parameters were as: flow rate of the polymer solution; $0.5 \mathrm{~mL} \mathrm{~h}^{-1}$, applied voltage; $11-12$ $\mathrm{kV}$ and tip to collector distance; $18 \mathrm{~cm}$, rotation speed of the collector; $2000 \mathrm{rpm}$. Then, the collected fibers were detached from the aluminum surface by spraying $\mathrm{MeOH}$ on fiber surface to ease the stress on fibers and inhibit the immediate stretching. Finally, the PIM-1 fiber was dried in an oven at $130^{\circ} \mathrm{C}$ under vacuum for overnight.

\subsection{Methods}

The molecular weight of PIM-1 was measured by an Agilent gelpermeation chromatograph (GPC) equipped with a ZORBAX PSM $300-S$ column, which was calibrated using polystyrene standard samples.THF was used as mobile phase at a flow rate of $1 \mathrm{mg}$ 
$\mathrm{mL}^{-1}$. Infrared (IR) spectra of samples were recorded on a Bruker Vertex 70 spectrometer. Samples were mixed with potassium bromide $(\mathrm{KBr})$ and pressed under the pressure of 8 tons to prepare pellets. Each sample was scanned 64 times at a resolution of $4 \mathrm{~cm}^{-1}$. Peak areas were calculated using Omnic software. ${ }^{1} \mathrm{H}$ nuclear magnetic resonance $\left({ }^{1} \mathrm{H}\right.$ NMR) spectra was collected using a Bruker DPX-400 MHz spectrometer at room temperature. Polymer solutions were prepared in $\mathrm{CDCl}_{3}$. Chemical shifts were referenced to tetramethylsilane (TMS). Thermo Scientific Flash 2000 series CHNS-O analyzer was used for elemental analysis. 2,5-(bis(5-tertbutyl-2-benzo-oxazol-2-yl))thiophene was used as a standard. Samples $(1-1.5 \mathrm{mg})$ were mixed with vanadium pentoxide (8-10 $\mathrm{mg}$ ) that was used as a catalyst for complete oxidation. $\mathrm{N}_{2}$ adsorption isotherms at $-196{ }^{\circ} \mathrm{C}$ were measured using an autosorb iQ gas sorption analyzer. A small amount of sample $(\sim 0.1 \mathrm{~g})$ was weighed into an analysis tube and degassed under high vacuum at $120^{\circ} \mathrm{C}$ for $960 \mathrm{~min}$. Analysis was conducted after reweighing the degassed sample. Brunauer-Emmet-Teller (BET) surface areas were calculated from $\mathrm{N}_{2}$ adsorption isotherms by multi-point analysis. Scanning electron microscopy (SEM) images were recorded using a FEI Quanta 200 FEG scanning electron microscope. After coating samples with $5 \mathrm{~nm} \mathrm{Au-Pt} \mathrm{imaging} \mathrm{and} \mathrm{the} \mathrm{analysis} \mathrm{was} \mathrm{performed} \mathrm{at}$ $10 \mathrm{kV}$. The diameters of electrospun fibers were quantified using Image software by measuring about 100 different fibers. Thermogravimetric analyzer TGA Q500 (TA Instruments) was used to investigate the changes on the thermal resistance of polymer samples. Samples were heated from 30 to $600{ }^{\circ} \mathrm{C}$ at a heating rate of $10^{\circ} \mathrm{C} \mathrm{min}{ }^{-1}$ under nitrogen atmosphere. Deionized water $(0.4 \mu \mathrm{L})$ was automatically dropped on the samples and Laplace-Young fitting was applied on contact angle measurements. The measurements were repeated 5 times for an average value using Dataphysics contact angle system OCA.

\subsection{Aniline adsorption from air}

Powder, fiber and film forms of PIM-1 were used for trapping aniline. $1 \mathrm{~mL}$ of aniline was placed in $50 \mathrm{~mL}$ glass vial then adsorbents were placed in this vial and sealed with parafilm. The samples kept for $24 \mathrm{~h}$ at room temperature to ensure maximum adsorption occurred. Then they were removed from glass vial and kept under suction hood for a certain period.

\subsection{Aniline adsorption from aqueous system}

For aniline adsorption studies, aqueous stock solution of aniline was prepared in deionized water. Different concentrations were prepared by dilution of the stock solution with deionized water. Calibration solutions were prepared from 200 to $1.6875 \mathrm{mg} \mathrm{L}^{-1}$ and their absorbance were measured using a Varian Cary 100 Bio spectrometer. Value of $\lambda_{\max }$ for aniline was taken as $280 \mathrm{~nm}$ and specific absorption coefficients, $a$, was determined as $0.014 \mathrm{~L}$ $\mathrm{mg}^{-1} \mathrm{~cm}^{-1}$. An exact amount of oven-dried adsorbent $(\sim 5.0 \mathrm{mg})$ was placed in $20 \mathrm{~mL}$ of $50 \mathrm{mg} \mathrm{L}^{-1}$ aniline solution. The solution (at natural $\mathrm{pH}$ ) containing the adsorbent was stirred well with a magnetic stirrer for 4-72 h. $2 \mathrm{~mL}$ aliquots were taken by syringe and filtered through a PTFE hydrophobic filter $(0.45 \mathrm{~mm})$ when powder from used as an adsorbent. The mass of aniline adsorbed by the polymer, $q_{\mathrm{e}}\left(\mathrm{mg} \mathrm{g}^{-1}\right)$, was determined from the absorbance of the aniline solution before contact with polymer, $A_{0}$, and the absorbance of the aniline solution after reaching equilibrium with the polymer, $A_{\mathrm{e}}$, using Eq. (1).

$q_{e}=\frac{\left(A_{0}-A_{e}\right) V}{a l m}$

where $V$ is the total volume of aniline solution, $l$ is the path length in the spectrometer and $m$ is the total mass of polymer.
For adsorption/desorption experiment $25 \mathrm{mg}$ PIM-1 fiber was placed in $20 \mathrm{~mL}$ of $200 \mathrm{mg} \mathrm{L}^{-1}$ aniline solution and it was stirred until reaching the equilibrium. Following this, desorption was performed using ethanol and value of $\lambda_{\max }$ for aniline in ethanol was taken as $286 \mathrm{~nm}$ and specific absorption coefficients, $a$, was determined as $0.0158 \mathrm{~L} \mathrm{mg}^{-1} \mathrm{~cm}^{-1}$.

\section{Result and discussion}

\subsection{Structural characterization}

Synthesis of PIM-1 has a long history and several methods have been introduced for PIM-1 preparation [15,45]. PIM-1 can be produced by using commercial monomers and as synthesized PIM-1 shows significant fluorescent yellow color. The PIM-1 used in this study has molecular weight $\left(M_{\mathrm{w}}\right)$ of $189 \mathrm{kDa}$ and it shows narrow PDI of 1.78 . The structure of and purity of PIM-1 were confirmed using FT-IR and ${ }^{1}$ H NMR spectroscopy techniques [44]. FT-IR spectrum of PIM-1 is depicted in Fig. 1(a) which shows characteristic nitrile (CN) stretches at $2240 \mathrm{~cm}^{-1}$ along with aromatic and aliphatic $\mathrm{C}-\mathrm{H}$ stretches around $3000 \mathrm{~cm}^{-1}$. ${ }^{1} \mathrm{H}$ NMR spectrum of PIM-1 is displayed in Fig. 1(b) showing four different proton environments. Thermal properties of PIM-1 are studied using thermogravimetric analysis technique that shows polymer is thermally stable and it starts degrading at $450^{\circ} \mathrm{C}$ (Fig. 1c). This behavior explained as polymer backbone degradation.

\subsection{Electrospinning of PIM-1 fibers}

Previous studies have reported the preparation of bead-free electrospun PIM-1 fibers by using 7 to $10 \%$ polymer in tetrachloroethane solutions with 127 and $292 \mathrm{kDa}$ molecular weight of PIM-1 polymer [40-42]. In the present study, we have employed the PIM-1 with a molecular weight of $189 \mathrm{kDa}\left(M_{\mathrm{w}}\right)$ with a narrow PDI (1.78). However, we only managed to produce fibers with over $23 \%(\mathrm{w} / \mathrm{v})$ polymer solution in the same solvent (tetrachloroethane). Moreover, wetting, is observed when the electrospun fibers were collected on the rotating drum at $100 \mathrm{rpm}$ as reported in previous studies [40-42]. This was overcome by increasing the rotation speed of drum collector to $2000 \mathrm{rpm}$ which also enables the formation of completely dried solid fibers with aligned fiber morphology. Following the electrospinning, polymer sticks on the surface of the aluminum foil which makes difficult to detach the fibers from the surface without giving a physical damage. Thus, the sample was treated with methanol for a short period of time in order to avoid the physical damage, since PIM1 swells reversibly in the presence of alcohol and it was dried afterwards $[14,15,46]$. Fig. 2(a) displays the digital image of fluorescent, self-standing fibrous electrospun PIM-1 and SEM images of beadfree, rounded and aligned PIM-1 fibers are shown in Fig. 2(b). The average fiber diameters were found $2.07 \pm 0.52 \mu \mathrm{m}$ for this polymer under the applied conditions and a relatively uniform fiber diameter distribution has been attained (Fig. 2c).

\subsection{Aniline adsorption from air}

PIM-1 has a high surface area, making it a promising candidate for adsorption studies. BET surface area measurements showed that PIM-1 powder and fiber have the same apparent surface area around $770 \mathrm{~m}^{2} \mathrm{~g}^{-1}$ and film form of PIM-1 has slightly lower surface area with $720 \mathrm{~m}^{2} \mathrm{~g}^{-1}$. All PIM-1 samples show type I isotherm at low pressure indicating significant microporosity. They also display hysteresis on desorption that may point out polymer swelling. $\mathrm{N}_{2}$ adsorption/desorption isotherms and pore parameters data are provided in Supplementary information in Figs. S1-5 and Tables 

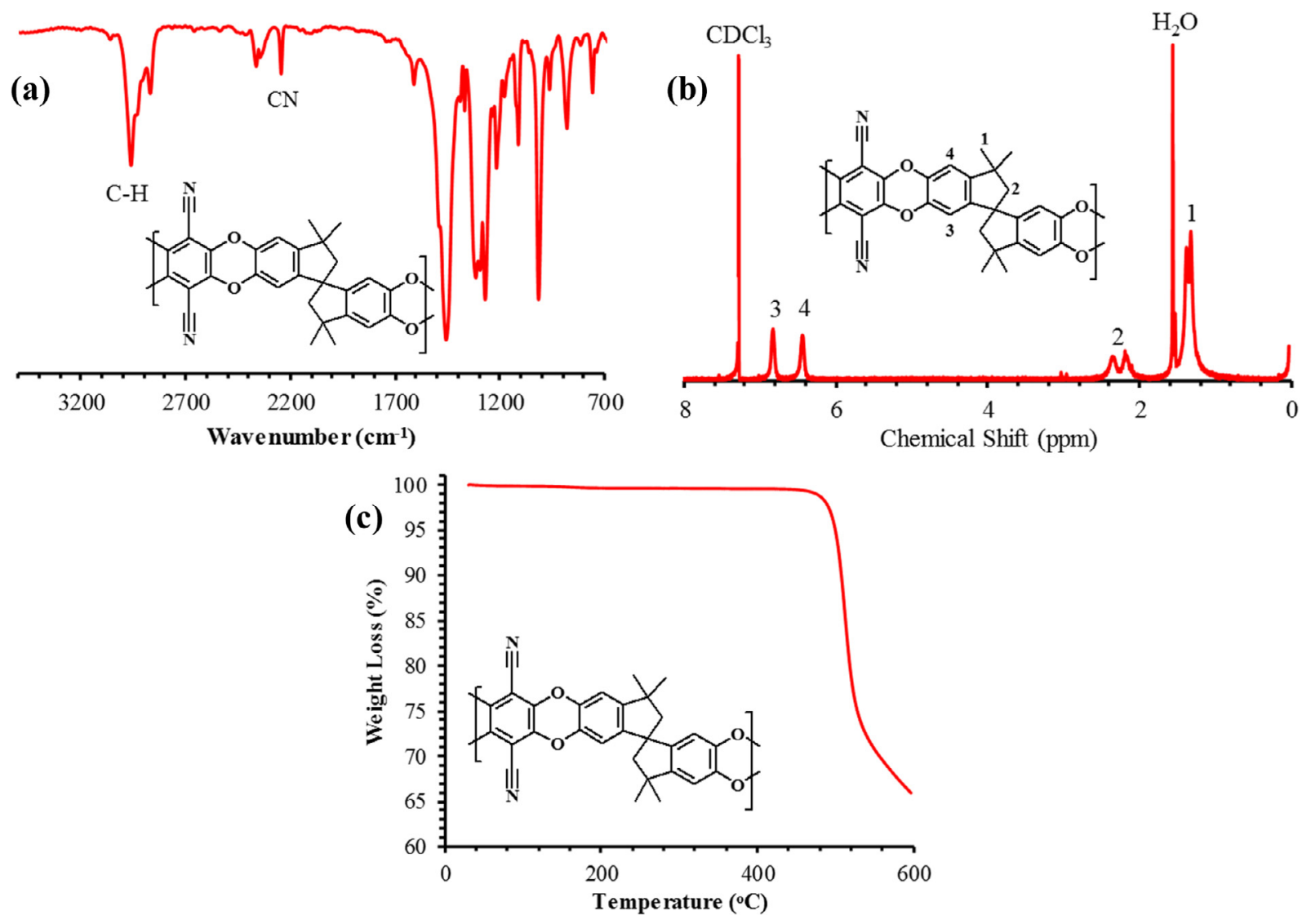

Fig. 1. (a) FT-IR spectrum, (b) ${ }^{1} \mathrm{H}$ NMR Spectrum, (c) TGA curve of PIM-1 powder [44].
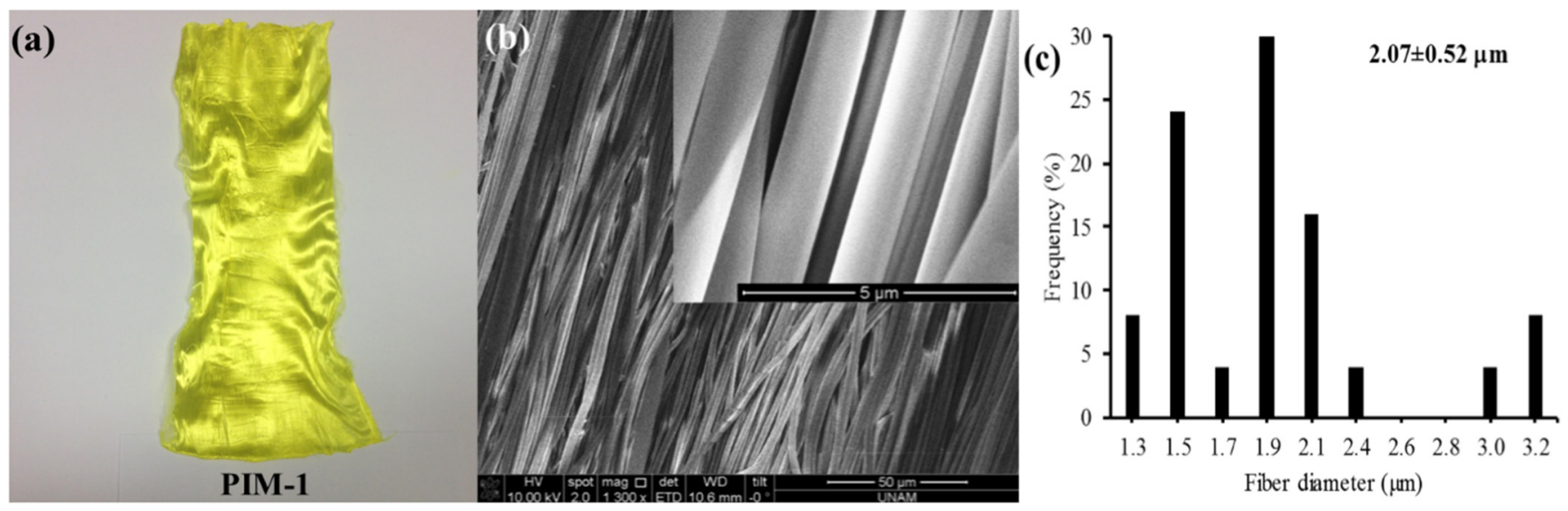

Fig. 2. (a) Digital image, (b) SEM images and (c) fiber diameter distribution of electrospun PIM-1 fiber.

S1-5. It has been reported that PIM-1 has high affinity for organic species and effectively used for removal of organic contaminants $[41,47]$. Thus, we have investigated the adsorption of aniline from air by electrospun PIM-1 fibers and compare the results with powder and film form of it. ${ }^{1} \mathrm{H}$ NMR and TGA were used effectively to quantify the amount of aniline trapped in the PIM-1 matrix. Fig. 3 exhibits the ${ }^{1} \mathrm{H}$ NMR spectra of PIM- 1 in $\mathrm{CDCl}_{3}$ before and after aniline adsorption. It can be clearly seen that aniline adsorbed PIM-1 shows distinct aromatic protons between 6 and 8 ppm along with amine protons $\left(-\mathrm{NH}_{2}\right)$ at $3.7 \mathrm{ppm}$. Thus, the integration of amine signal of aniline and the aromatic proton of PIM- $1\left(\mathrm{Ar}-\mathrm{H}_{4}\right)$ may assist to calculate the amount of aniline which is trapped in
PIM-1. The aniline adsorption capacity of PIM-1s was found from ${ }^{1} \mathrm{H}$ NMR based on Eq. S6 in Supplementary information. The highest uptakes were found 558, 774 and $871 \mathrm{mg} \mathrm{g}^{-1}$ for powder, film and fiber PIM-1 respectively.

The adsorption of aniline by PIM- 1 was also observed by TGA which indicates a great adsorption performance. Fig. 4 shows the TGA curves of film, powder and fiber form of PIM- 1 before and after the adsorption. While powder and film form do not show any weight loss before $450{ }^{\circ} \mathrm{C}$, electrospun fiber PIM-1 shows a slight weight loss (2\%) between 120 and $190{ }^{\circ} \mathrm{C}$ due to the trace solvent content. Hence, solvent correction is applied for fiber PIM-1. The aniline adsorbed samples showing significant weight 

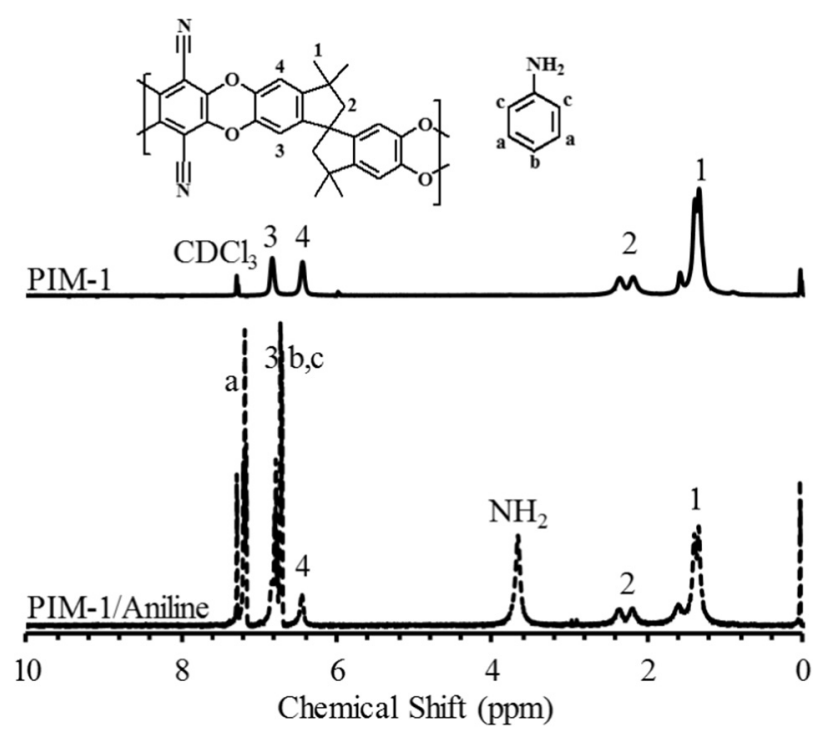

Fig. 3. ${ }^{1} \mathrm{H}$ NMR spectra of PIM-1 (solid line) and aniline adsorbed PIM-1 (dashed line) fibers in $\mathrm{CDCl}_{3}$.

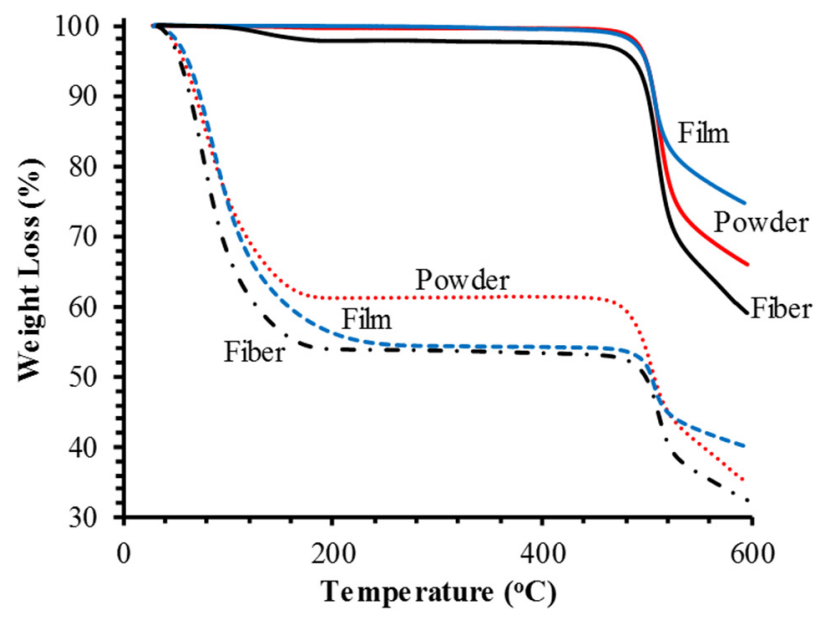

Fig. 4. TGA curves of powder, film, and fiber, form of PIM-1 before and after aniline adsorption. Solid lines indicate samples before in contact with aniline and dashed lines indicate samples after in contact with aniline within $24 \mathrm{~h}$.

loss up to $200{ }^{\circ} \mathrm{C}$ which was assigned as aniline content of PIM-1. Thus, the aniline adsorption capacity of PIM-1s was calculated from TGA based on Eq. $S 9$ in Supplementary information. The highest uptakes were found 634,779 and $818 \mathrm{mg} \mathrm{g}^{-1}$ aniline for powder, film and fiber PIM-1 respectively. In addition, further characterization, the comparison of calculated\% removal of aniline from NMR and TGA data and digital image of PIM-1 fiber before and after aniline adsorption are provided in Supplementary information in Figs. S6-S8. It has also been noted that the fluorescence behavior of PIM-1 is quenched after aniline adsorption (Fig. S8).

\subsection{Aniline adsorption from aqueous system}

Following the aniline adsorption data obtained by PIM-1 from air, the adsorption of aniline from water has also been studied. The PIM-1 samples are also able to adsorb aniline from water. The aniline adsorption maximums of PIM- 1 s were found $69 \pm 2.0$, $78 \pm 5.4,85 \pm 2.5 \mathrm{mg} \mathrm{g}^{-1}$ for film, fiber and powder samples respectively from $50 \mathrm{mg} \mathrm{L}^{-1}$ aniline solutions (Fig. 5a). Even though powder PIM-1 can adsorb slightly higher amount of aniline, the separation of adsorbent from solution requires additional filtration step which makes difficult to continue and examine time profile of adsorption precisely. Thus, the adsorption was studied over the time for fiber and film PIM-1s. Fig. 5(b) exhibits that fiber PIM-1 can reach equilibrium within $5 \mathrm{~h}$, although film PIM-1 requires much longer contact time $(72 \mathrm{~h})$ to reach the equilibrium. This was first considered by sample's hydrophobicity, and contact angle measurement has showed $84 \pm 2^{\circ}$ for film and $134 \pm 8^{\circ}$ for fiber PIM-1. The results are in good agreement with previous studies. [42,48] Digital images of water drops on PIM-1 film and fiber are provided in Supplementary information in Fig. S9. Then, the reason for such a slow kinetic was thought to be related to density of the PIM-1 samples. Film form is denser than fiber and powder form, thus, it may follow slower kinetic. The kinetic data were aimed to analyzed by pseudo-first-order and pseudo-second-order rate models. However, the data is not sufficient enough to distinguish the precise model. The results confirm the more rapid adsorption by fiber PIM-1. The kinetic data are supported in Supplementary information (Tables S6-7 and Figs. S10-11).

The adsorption capacity of adsorbents can be examined by the adsorption isotherms [49]. In order to examine the adsorption capacity of electrospun fiber PIM- 1 with other materials, the isotherm experiments were conducted and experimental maximum adsorption capacity was found $138 \mathrm{mg} \mathrm{g}^{-1}$ for PIM-1 fiber (Fig. 5c and Table S8). Data was analyzed using Langmuir and Freundlich models as it displayed in Fig. S12. It was found that the Langmuir model is the best model for describing the adsorption of aniline on PIM-1 fiber as the adj. $\mathrm{R}^{2}$ of aniline is greater than that of Freundlich model, implying the adsorption follows monolayer coverage, and the surface is relatively homogeneous. Similar observation has been reported for orange II adsorption by PIM-1 powder from an aqueous system [50].

The constants of isotherm models are given in Supplementary information in Table S9 and theoretical maximum adsorption capacity was found as $161.2 \mathrm{mg} \mathrm{g}^{-1}$ which is slightly higher than experimental maximum adsorption capacity. In addition to fast kinetic, electrospun PIM-1 fibers are stable in water and the fiber morphology is kept after the adsorption. Moreover, regeneration of adsorbent has also been achieved by using acidic methanol treatment for a short period of time. SEM images of PIM- 1 after 3 cycle of adsorption/desorption is provided in Supplementary information (Fig. S13). However, using acidic methanol solution to desorb the aniline that was adsorbed on PIM-1 surface was not found reliable in terms of quantification. As aniline protonated in acidic medium creating a decent calibration curve does not seem possible. Fig. S14 in Supplementary information displays the UV spectra of aniline obtained from acidic methanol solution for $370 \mathrm{ppm}$ and $185 \mathrm{ppm}$ concentration that limit to obtain specific absorption coefficient, $a$, by simple calibration. For that reason, ethanol solution is used for desorption experiment as PIM-1 can swell reversibly in the presence of alcohol. The alcohol treatment method is widely used to remove residuals from PIM-1 structure in gas separation [51-53]. Thus, adsorbed aniline was desorbed into ethanol solution within $1 \mathrm{~h}$. Note that, Value of $\lambda_{\max }$ for aniline in ethanol was found as $286 \mathrm{~nm}$ (Fig. S14), due to slight shift in $\lambda_{\max }$ value specific absorption coefficient was also recalculated for ethanol solution. Water and ethanol calibration curves are also provided in Supplementary information in Fig. S15. Regeneration of PIM-1 fiber and adsorption/desorption efficiency can be seen in Fig. 5d that shows PIM-1 fiber maintains $85 \%$ of its adsorption capacity after 4 cycles. Note that, PIM-1 is soluble in chloroform, thus, in the case of any significant reduction in adsorption capacity it can be dissolved in chloroform and re-precipitate from methanol. Following regeneration of polymer, fresh PIM-1 fiber can be obtained by electrospinning repeatedly until polymer plasticize. The value of $q_{\mathrm{m}}$ is compared with other adsorbents and it was higher than that 
(a)
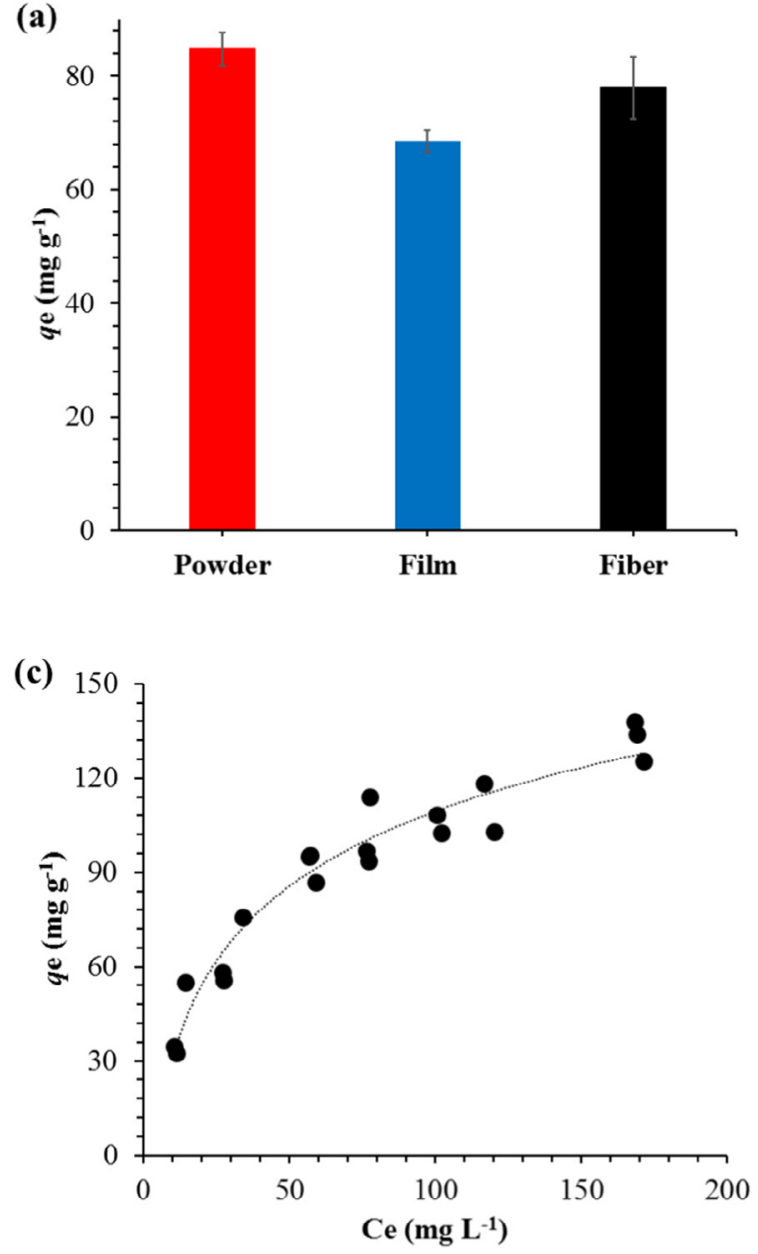

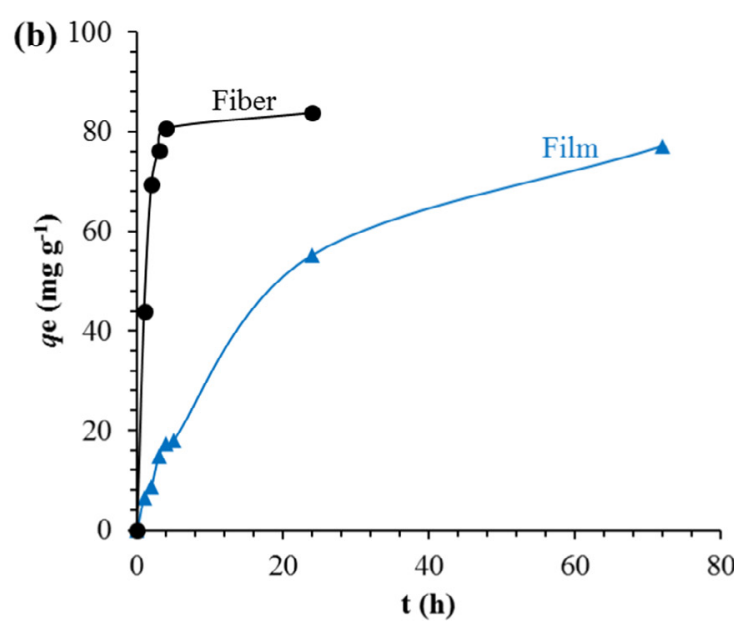

(d)

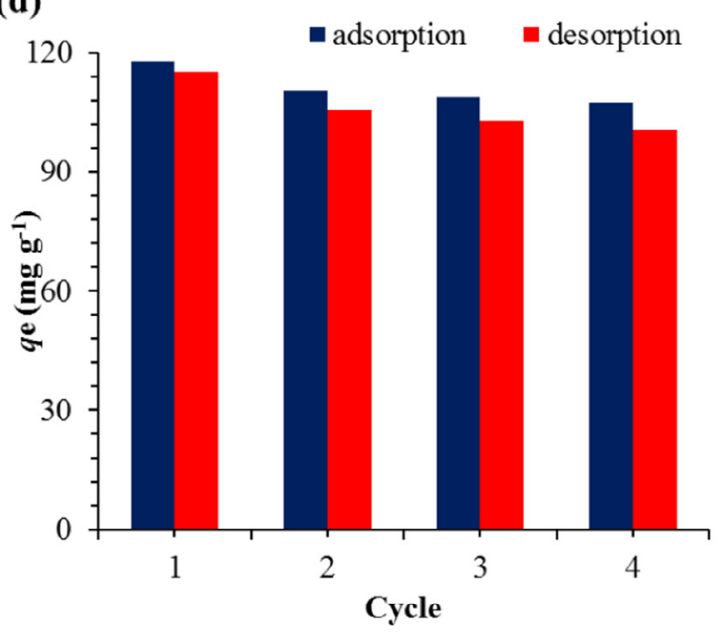

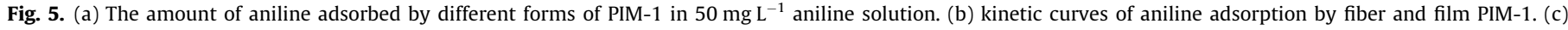
Adsorption isotherm of aniline on PIM-1 fiber. (d) Adsorption/desorption efficiency of fiber PIM-1 from water and ethanol solutions.

Table 1

Comparison of the experimental conditions, BET surface areas, pore parameters and adsorption capacities of promising adsorbents towards aniline.

\begin{tabular}{|c|c|c|c|c|c|c|c|}
\hline \multirow[t]{2}{*}{ Adsorbent } & \multicolumn{2}{|c|}{$\begin{array}{l}\text { Experimental } \\
\text { conditions }\end{array}$} & \multirow[t]{2}{*}{$\begin{array}{l}\text { BET surface } \\
\text { area }\left(\mathrm{m}^{2} \mathrm{~g}^{-1}\right)\end{array}$} & \multirow[t]{2}{*}{$\begin{array}{l}\text { Pore diameter of } \\
\text { adsorbent }(\mathrm{nm})\end{array}$} & \multirow[t]{2}{*}{$\begin{array}{l}\text { Total pore } \\
\text { volume }\left(\mathrm{cm}^{3} / \mathrm{g}\right)\end{array}$} & \multirow[t]{2}{*}{$q_{\mathrm{m}}\left(\mathrm{mg} \mathrm{g}^{-1}\right)$} & \multirow[t]{2}{*}{ Ref } \\
\hline & $\mathrm{T}\left({ }^{\circ} \mathrm{C}\right)$ & $\mathrm{pH}$ & & & & & \\
\hline Activated carbon/chitosan composite & 20 & 7 & n.a & n.a & n.a & 22.9 & [54] \\
\hline $\mathrm{PAM} / \mathrm{SiO}_{2}$ & 20 & 8 & n.a & n.a & n.a & 52 & [13] \\
\hline Sawdust- $\beta-C D$ & 15 & 7 & 0.11 & n.a & $1.18 \times 10^{-4}$ & 84 & [55] \\
\hline $\mathrm{Fe}_{3} \mathrm{O}_{4}$-activated carbon & 20 & 6 & 671.2 & 1.2 & 4.87 & 90.9 & {$[56]$} \\
\hline Modified jute fiber & 25 & 7 & 0.58 & 2.7 & $3.58 \times 10^{-4}$ & 125 & [57] \\
\hline Electrospun PIM-1 fiber (this work) & 20 & 6 & 767 & 2.9 & 0.565 & 161.2 & This work \\
\hline Phenol-modified hyper-cross-linked resins & 25 & n.a & 1219 & n.a & 0.919 & 169.2 & [58] \\
\hline
\end{tabular}

of many other adsorbents reported in the literature. Table 1 shows the comparison of the maximum adsorption capacities, surface areas and pore parameters of different adsorbents towards aniline under the applied conditions.

Note that, adsorption capacity of PIM-1 fiber from air is greater than that of from water. Since in air adsorption experiment, the environment is mainly including aniline molecules so minimal interruption occurs for the interaction between PIM-1 and aniline molecules in the gas form. On the other hand, water inhibits the interaction between PIM-1 and aniline molecules in liquid form. As PIM-1 knows as hydrophobic polymer. Water contact angle of PIM-1 fiber is found $134 \pm 8^{\circ}$ (Fig. S9) that is possibly inhibits the proper interaction with aniline molecules in water. Moreover, the interaction between water-aniline molecules are possibly higher than the interaction between PIM-1-aniline molecules causing less adsorption from water but the material is still promising for an adsorption from mainstream not only as an air filter.

\section{Conclusion}

In this study we have prepared electrospun PIM-1 fibers in order to investigate the aniline adsorption ability and data was compared with powder and film form of PIM-1. All forms of PIM1 show great adsorption performances for aniline adsorption. Maximum aniline adsorption capacities from air were found 558, 774 
and $871 \mathrm{mg} \mathrm{g}^{-1}$ for powder, film and fiber form of PIM-1. The aniline adsorption from aqueous solutions were also investigated. Electrospun PIM-1 fibrous mat shows fairly fast adsorption within $5 \mathrm{~h}$ compare to PIM-1 film. The experimental maximum adsorption capacity $\left(q_{\mathrm{e}}\right)$ of electrospun PIM-1 fibrous mat was found as 138 $\mathrm{mg} \mathrm{g}^{-1}$, while theoretical maximum adsorption capacity $\left(q_{\mathrm{m}}\right)$ was calculated as $161.2 \mathrm{mg} \mathrm{g}^{-1}$ that surpasses most of the adsorbents reported in literature. Langmuir and Freundlich isotherm models have also been studied and Langmuir model found more appropriate for aniline adsorption on electrospun PIM-1 fibers. The study demonstrated that electrospun PIM-1 fibers can be a potential candidate for adsorptive removal of aniline both in air and aqueous media.

\section{Appendix A. Supplementary material}

Supplementary data associated with this article can be found, in the online version, at https://doi.org/10.1016/j.jcis.2018.01.069.

\section{References}

[1] Y. Cui, X.-Y. Liu, T.-S. Chung, M. Weber, C. Staudt, C. Maletzko, Removal of organic micro-pollutants (phenol, aniline and nitrobenzene) via forward osmosis (FO) process: evaluation of FO as an alternative method to reverse osmosis (RO), Water Res. 91 (2016) 104-114.

[2] M. Akkari, P. Aranda, A. Mayoral, M. García-Hernández, A. Ben Haj Amara, E. Ruiz-Hitzky, Sepiolite nanoplatform for the simultaneous assembly of magnetite and zinc oxide nanoparticles as photocatalyst for improving removal of organic pollutants, J. Hazard. Mater. 340 (2017) 281-290.

[3] Z. Liang, W. Shi, Z. Zhao, T. Sun, F. Cui, Enhanced removal and adsorption characters of aniline by the inorganically modified mesoporous silica nanospheres, Colloids Surf. A 513 (2017) 250-258.

[4] P.M. Słomkiewicz, B. Szczepanik, M. Garnuszek, Determination of adsorption isotherms of aniline and 4-chloroaniline on halloysite adsorbent by inverse liquid chromatography, Appl. Clay Sci. 114 (2015) 221-228.

[5] N. Tao, G. Liu, L. Bai, L. Tang, C. Guo, Genotoxicity and growth inhibition effects of aniline on wheat, Chemosphere 169 (2017) 467-473.

[6] A. Celebioglu, H.S. Sen, E. Durgun, T. Uyar, Molecular entrapment of volatile organic compounds (VOCs) by electrospun cyclodextrin nanofibers, Chemosphere 144 (2016) 736-744.

[7] C. Chen, X. Geng, W. Huang, Adsorption of 4-chlorophenol and aniline by nanosized activated carbons, Chem. Eng. J. 327 (2017) 941-952.

[8] P.C.C. Faria, J.J.M. Órfão, M.F.R. Pereira, Ozonation of aniline promoted by activated carbon, Chemosphere 67 (4) (2007) 809-815.

[9] F. Orshansky, N. Narkis, Characteristics of organics removal by PACT simultaneous adsorption and biodegradation, Water Res. 31 (3) (1997) 391 398.

[10] C. Causserand, P. Aimar, J.P. Cravedi, E. Singlande, Dichloroaniline retention by nanofiltration membranes, Water Res. 39 (8) (2005) 1594-1600.

[11] A. Fakhri, Adsorption characteristics of graphene oxide as a solid adsorbent for aniline removal from aqueous solutions: kinetics, thermodynamics and mechanism studies, J. Saudi Chem. Soc. 21 (2017) S52-S57.

[12] Q. Hu, P. Wang, J. Jiang, H. Pan, D.-W. Gao, Column adsorption of aniline by surface modified jute fiber and its regeneration property, J. Environ. Chem. Eng. 4 (2) (2016) 2243-2249.

[13] F. An, X. Feng, B. Gao, Adsorption of aniline from aqueous solution using novel adsorbent PAM $/ \mathrm{SiO}_{2}$, Chem. Eng. J. 151 (1) (2009) 183-187.

[14] P.M. Budd, K.J. Msayib, C.E. Tattershall, B.S. Ghanem, K.J. Reynolds, N.B. McKeown, D. Fritsch, Gas separation membranes from polymers of intrinsic microporosity, J. Membr. Sci. 251 (1-2) (2005) 263-269.

[15] P.M. Budd, B.S. Ghanem, S. Makhseed, N.B. McKeown, K.J. Msayib, C.E. Tattershall, Polymers of intrinsic microporosity (PIMs): robust, solutionprocessable, organic nanoporous materials, Chem. Commun. 2 (2004) 230231.

[16] P.M. Budd, N.B. McKeown, D. Fritsch, Free volume and intrinsic microporosity in polymers, J. Mater. Chem. 15 (20) (2005) 1977-1986.

[17] Y. Wang, B. McKeown, J. Msayib, A. Turnbull, W. Samuel, Laser chemosensor with rapid responsivity and inherent memory based on a polymer of intrinsic microporosity, Sensors 11 (3) (2011) 2478-2487.

[18] C. Thomas, E. Trend, A. Rakow, S. Wendland, J. Poirier, M. Paolucci, Optica sensor for diverse organic vapors at ppm concentration ranges, Sensors 11 (3) (2011).

[19] N.B. McKeown, P.M. Budd, Polymers of intrinsic microporosity (PIMs): organic materials for membrane separations, heterogeneous catalysis and hydrogen storage, Chem. Soc. Rev. 35 (8) (2006) 675-683.

[20] H.J. Mackintosh, P.M. Budd, N.B. McKeown, Catalysis by microporous phthalocyanine and porphyrin network polymers, J. Mater. Chem. 18 (5) (2008) 573-578.
[21] P.M. Budd, N.B. McKeown, B.S. Ghanem, K.J. Msayib, D. Fritsch, L. Starannikova, N. Belov, O. Sanfirova, Y. Yampolskii, V. Shantarovich, Gas permeation parameters and other physicochemical properties of a polymer of intrinsic microporosity: Polybenzodioxane PIM-1, J. Membr. Sci. 325 (2) (2008) 851860.

[22] P.M. Budd, N.B. McKeown, Highly permeable polymers for gas separation membranes, Polym. Chem. 1 (1) (2010) 63-68.

[23] A.V. Maffei, P.M. Budd, N.B. McKeown, Adsorption studies of a microporous phthalocyanine network polymer, Langmuir 22 (9) (2006) 4225-4229.

[24] L.M. Robeson, The upper bound revisited, J. Membr. Sci. 320 (1) (2008) 390400.

[25] P. Li, T.S. Chung, D.R. Paul, Gas sorption and permeation in PIM-1, J. Membr. Sci. 432 (2013) 50-57.

[26] M. Žák, M. Klepic, L.Č. Štastná, Z. Sedláková, H. Vychodilová, Š. Hovorka, K. Friess, A. Randová, L. Brožová, J.C. Jansen, et al., Selective removal of butanol from aqueous solution by pervaporation with a PIM-1 membrane and membrane aging, Sep. Purif. Technol. 151 (2015) 108-114.

[27] V. Adymkanov, P. Yampol'skii, M. Polyakov, M. Budd, J. Reynolds, B. McKeown, J. Msayib, Pervaporation of alcohols through highly permeable PIM-1 polymer films, Polym. Sci. Series A 50 (4) (2008) 444-450.

[28] D. Fritsch, P. Merten, K. Heinrich, M. Lazar, M. Priske, High performance organic solvent nanofiltration membranes: development and thorough testing of thin film composite membranes made of polymers of intrinsic microporosity (PIMs), J. Membr. Sci. 401-402 (2012) 222-231.

[29] S. Tsarkov, V. Khotimskiy, P.M. Budd, V. Volkov, J. Kukushkina, A. Volkov, Solvent nanofiltration through high permeability glassy polymers: effect of polymer and solute nature, J. Membr. Sci. 423-424 (2012) 65-72.

[30] S. Anokhina, A. Yushkin, M. Budd, V. Volkov, Application of PIM-1 for solvent swing adsorption and solvent recovery by nanofiltration (Part 2), Sep. Purif. Technol. 156 (2015) 683-690.

[31] L. Jue, V. Breedveld, P. Lively, Defect-free PIM-1 hollow fiber membranes, J. Membr. Sci. 530 (Suppl. C) (2017) 33-41.

[32] W.F. Yong, F.Y. Li, Y.C. Xiao, T.S. Chung, Y.W. Tong, High performance PIM-1/ Matrimid hollow fiber membranes for $\mathrm{CO}_{2} / \mathrm{CH}_{4}, \mathrm{O}_{2} / \mathrm{N}_{2}$ and $\mathrm{CO}_{2} / \mathrm{N}_{2}$ separation, J. Membr. Sci. 443 (2013) 156-169.

[33] T. Uyar, E. Kny, Electrospun Materials for Tissue Engineering and Biomedical Applications: Research, Design and Commercialization, Elsevier, Woodhead Publishing, 2017.

[34] S. Ramakrishna, K. Fujihara, W.-E. Teo, T.-C. Lim, Z. Ma, An Introduction to Electrospinning and Nanofibers, World Scientific, 2005.

[35] H. Wendorff, S. Agarwal, A. Greiner, Electrospinning: Materials, Processing, and Applications, John Wiley \& Sons, 2012.

[36] N. Bhardwaj, S.C. Kundu, Electrospinning: a fascinating fiber fabrication technique, Biotechnol. Adv. 28 (3) (2010) 325-347.

[37] F. Kayaci, C. Ozgit-Akgun, N. Biyikli, T. Uyar, Surface-decorated ZnO nanoparticles and $\mathrm{ZnO}$ nanocoating on electrospun polymeric nanofibers by atomic layer deposition for flexible photocatalytic nanofibrous membranes, RSC Adv. 3 (19) (2013) 6817-6820.

[38] A. Celebioglu, F. Kayaci-Senirmak, S. Ipek, E. Durgun, T. Uyar, Polymer-free nanofibers from vanillin/cyclodextrin inclusion complexes: high thermal stability, enhanced solubility and antioxidant property, Food Funct. 7 (7) (2016) 3141-3153.

[39] A. Senthamizhan, B. Balusamy, T. Uyar, Glucose sensors based on electrospun nanofibers: a review, Anal. Bioanal. Chem. 408 (5) (2016) 1285-1306.

[40] J.S. Bonso, G.D. Kalaw, J.P. Ferraris, High surface area carbon nanofibers derived from electrospun PIM-1 for energy storage applications, J. Mater. Chem. A 2 (2) (2014) 418-424.

[41] C. Zhang, P. Li, B. Cao, Electrospun polymer of intrinsic microporosity fibers and their use in the adsorption of contaminants from a nonaqueous system, J. Appl. Polym. Sci. 133 (22) (2016)

[42] C. Zhang, P. Li, B. Cao, Electrospun microfibrous membranes based on PIM-1/ POSS with high oil wettability for separation of oil-water mixtures and cleanup of oil soluble contaminants, Ind. Eng. Chem. Res. 54 (35) (2015) $8772-$ 8781.

[43] E. Lasseuguette, M.-C. Ferrari, Development of microporous electrospun PIM-1 fibres, Mater. Lett. 177 (2016) 116-119.

[44] B. Satilmis, M. Budd, T. Uyar, Systematic hydrolysis of PIM-1 and electrospinning of hydrolyzed PIM-1 ultrafine fibers for an efficient removal of dye from water, React. Funct. Polym. 121 (Suppl. C) (2017) 67-75.

[45] N. Du, J. Song, G.P. Robertson, I. Pinnau, M.D. Guiver, Linear high molecular weight ladder polymer via fast polycondensation of 5,5',6,6'-tetrahydroxy3,3,3',3'-tetramethylspirobisindane with 1,4-dicyanotetrafluorobenzene, Macromol. Rapid Commun. 29 (10) (2008) 783-788.

[46] M.L. Jue, C.S. McKay, B.A. McCool, M.G. Finn, R.P. Lively, Effect of nonsolvent treatments on the microstructure of PIM-1, Macromolecules 48 (16) (2015) 5780-5790.

[47] C.A. Jeffs, M.W. Smith, C.A. Stone, C.G. Bezzu, K.J. Msayib, N.B. McKeown, S.P. Perera, A polymer of intrinsic microporosity as the active binder to enhance adsorption/separation properties of composite hollow fibres, Microporous Mesoporous Mater. 170 (2013) 105-112.

[48] B. Satilmis, P.M. Budd, Base-catalysed hydrolysis of PIM-1: amide versus carboxylate formation, RSC Adv. 4 (94) (2014) 52189-52198.

[49] Y. Guan, H. Qian, J. Guo, S. Yang, X. Wang, S. Wang, Y. Fu, Synthesis of acidified palygorskite/BiOI with exceptional performances of adsorption and visiblelight photoactivity for efficient treatment of aniline wastewater, Appl. Clay Sci. 114 (Suppl. C) (2015) 124-132. 
[50] M. Shakeel, K. Mehmood, M. Waseem, W. Rehman, K.H. Shah, M. Nawaz, Adsorption of methyl orange from aqueous solution by polymer of intrinsic microporosity: isotherms and kinetics study, J. Chem. Soc. Pak. 39 (3) (2017) 337-342.

[51] J.C. Jansen, P. Bernardo, F. Bazzarelli, G. Clarizia, P.M. Budd, Y. Yampolskii, Characterization of the gas transport in mixed matrix membranes based on polymers with intrinsic microporosity (PIMs), Procedia Eng. 44 (2012) 103105.

[52] A.F. Bushell, M.P. Attfield, C.R. Mason, P.M. Budd, Y. Yampolskii, L. Starannikova, A. Rebrov, F. Bazzarelli, P. Bernardo, J. Carolus Jansen, et al., Gas permeation parameters of mixed matrix membranes based on the polymer of intrinsic microporosity PIM-1 and the zeolitic imidazolate framework ZIF-8, J. Membr. Sci. 427 (2013) 48-62.

[53] M.R. Khdhayyer, E. Esposito, A. Fuoco, M. Monteleone, L. Giorno, J.C. Jansen, M. P. Attfield, P.M. Budd, Mixed matrix membranes based on UiO-66 MOFs in the polymer of intrinsic microporosity PIM-1, Sep. Purif. Technol. 173 (2017) 304-313.
[54] R. Huang, B. Yang, Q. Liu, Y. Liu, Simultaneous adsorption of aniline and $\mathrm{Cr}(\mathrm{VI})$ ion by activated carbon/chitosan composite, J. Appl. Polym. Sci. 131 (4) (2014) $\mathrm{n} / \mathrm{a}-\mathrm{n} / \mathrm{a}$.

[55] Q. Hu, D.-W. Gao, H. Pan, L. Hao, P. Wang, Equilibrium and kinetics of aniline adsorption onto crosslinked sawdust-cyclodextrin polymers, RSC Adv. 4 (75) (2014) 40071-40077.

[56] B. Kakavandi, A. Jonidi, R. Rezaei, S. Nasseri, A. Ameri, A. Esrafily, Synthesis and properties of $\mathrm{Fe}_{3} \mathrm{O}_{4}$-activated carbon magnetic nanoparticles for removal of aniline from aqueous solution: equilibrium, kinetic and thermodynamic studies, Iran. J. Environ. Health Sci. Eng. 10 (1) (2013) 19.

[57] D.-W. Gao, Q. Hu, H. Pan, J. Jiang, P. Wang, High-capacity adsorption of aniline using surface modification of lignocellulose-biomass jute fibers, Bioresource Technol. 193 (Suppl. C) (2015) 507-512.

58] W. Kuang, Y.-N. Liu, J. Huang, Phenol-modified hyper-cross-linked resins with almost all micro/mesopores and their adsorption to aniline, J. Colloid Interface Sci. 487 (2017) 31-37. 